\title{
Simultaneous observations of equatorial F-region plasma depletions over Brazil during the Spread-F Experiment (SpreadFEx)
}

\author{
P.-D. Pautet ${ }^{1}$, M. J. Taylor ${ }^{1}$, N. P. Chapagain ${ }^{1}$, H. Takahashi ${ }^{2}$, A. F. Medeiros ${ }^{3}$, F. T. São Sabbas ${ }^{2}$, and D. C. Fritts ${ }^{4}$ \\ ${ }^{1}$ Center for Atmospheric and Space Sciences, Utah State University, Logan, UT, USA \\ ${ }^{2}$ Instituto Nacional de Pesquisas Espaciais (INPE), São José dos Campos, São Paulo, Brazil \\ ${ }^{3}$ Universidade Federal de Campina Grande, Campina Grande, Paraiba, Brazil \\ ${ }^{4}$ NorthWest Research Associates, CoRA Division, Boulder, CO, USA
}

Received: 6 May 2008 - Revised: 6 February 2009 - Accepted: 6 February 2009 - Published: 8 June 2009

\begin{abstract}
From September to November 2005, the NASA Living with a Star program supported the Spread-F Experiment campaign (SpreadFEx) in Brazil to study the effects of convectively generated gravity waves on the ionosphere and their role in seeding Rayleigh-Taylor instabilities, and associated equatorial plasma bubbles. Several US and Brazilian institutes deployed a broad range of instruments (all-sky imagers, digisondes, photometers, meteor/VHF radars, GPS receivers) covering a large area of Brazil. The campaign was divided in two observational phases centered on the September and October new moon periods. During these periods, an Utah State University (USU) all-sky CCD imager operated at São João d'Aliança $\left(14.8^{\circ} \mathrm{S}, 47.6^{\circ} \mathrm{W}\right)$, near Brasilia, and a Brazilian all-sky CCD imager located at Cariri $\left(7.4^{\circ} \mathrm{S}\right.$, $36^{\circ} \mathrm{W}$ ), observed simultaneously the evolution of the ionospheric bubbles in the OI $(630 \mathrm{~nm})$ emission and the mesospheric gravity wave field. The two sites had approximately the same magnetic latitude $\left(9-10^{\circ} \mathrm{S}\right)$ but were separated in longitude by $\sim 1500 \mathrm{~km}$.
\end{abstract}

Plasma bubbles were observed on every clear night (17 from Brasilia and 19 from Cariri, with 8 coincident nights). These joint datasets provided important information for characterizing the ionospheric depletions during the campaign and to perform a novel longitudinal investigation of their variability. Measurements of the drift velocities at both sites are in good agreement with previous studies, however, the overlapping fields of view revealed significant differences in the occurrence and structure of the plasma bubbles, providing new evidence for localized generation. This paper summarizes the observed bubble characteristics important for re-

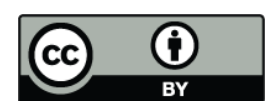

Correspondence to: P.-D. Pautet (dominiquepautet@gmail.com) lated investigations of their seeding mechanisms associated with gravity wave activity.

Keywords. Atmospheric composition and structure (Airglow and aurora) - Ionosphere (Equatorial ionosphere; Ionospheric irregularities)

\section{Introduction}

Since their first observation by ionosonde in the 1920s (Booker and Wells, 1938), equatorial spread-F (ESF) irregularities have been studied intensively because of their importance in understanding thermosphere-ionosphere coupling and their detrimental influence on radio communications. More recently, ESF has been shown to create significant errors in GPS position measurements at low-latitudes when the line-of-sight satellite signals pass through strong equatorial plasma bubbles (EPB) also termed depletions (e.g., Basu et al., 1999; Kelley et al., 2002).

Depletions are magnetic field-aligned regions where the density of the ionospheric plasma is reduced significantly compared to the surrounding plasma, that result from strong upwelling at the magnetic equator due to the Rayleigh-Taylor instability (Ossakow et al., 1981). As they develop, they may attain very high altitudes $(>1500 \mathrm{~km})$ at the magnetic equator (e.g., Mendillo and Tyler, 1983; Sahai et al., 1994), and then propagate poleward in the flux tubes (Sales et al., 1996), extending several thousands of kilometers down to dip latitudes greater than $\pm 15^{\circ}$ (Rohrbaugh et al., 1989). The structures are magnetically North-South aligned, exhibiting East-West widths ranging from tens of meters to a few hundred kilometers. ESF irregularities were first identified over Huancayo, Peru, and were defined as "spread in the ranges of the F-layer trace" in nighttime equatorial ionograms or spread-F. This

Published by Copernicus Publications on behalf of the European Geosciences Union. 


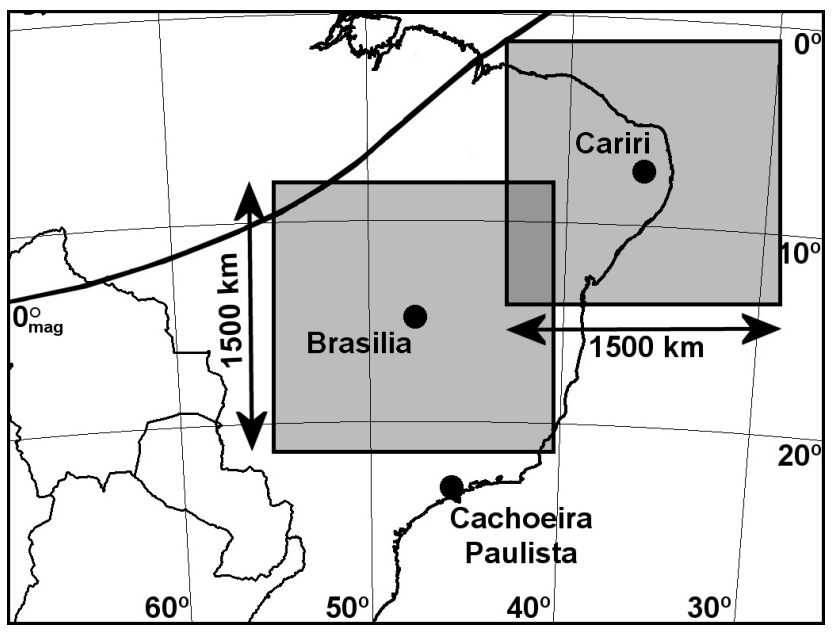

Fig. 1. Map of Brazil showing the all-sky imager locations during the SpreadFEx campaign and their proximity to the magnetic equator. The boxes represent the $1500 \times 1500 \mathrm{~km}$ area corresponding to the unwarped OI $(630 \mathrm{~nm})$ images for the Brasilia and Cariri sites, assuming an emission altitude of $250 \mathrm{~km}$.

term now generally refers to the composite effects produced by a broad range of equatorial F-region plasma irregularities (Ossakow, 1981).

Several techniques have been used to study this phenomenon, including remote sensing incoherent scatter radar, ionosonde, radio wave scintillations, rocket and satellite borne in-situ measurements (e.g., Batista et al., 1986; Basu et al., 1996; Jahn et al., 1997; Henderson et al., 2005). Depletions have also been extensively studied via their optical signatures in the F-region nightglow emissions mainly using photometers and imagers (e.g., Weber et al., 1978, Mendillo and Baumgardner, 1982, Sahai et al., 1994; Makela et al., 2004). Many theoretical and simulation studies of their properties and seasonal characteristics have also been carried out (e.g., Fejer et al., 1985; Haerendel et al., 1992; Abdu, 2001; Abdu et al., 2003; Kudeki et al., 2007).

ESF irregularities are generated at the bottomside of the Flayer by the sunset enhancement of the zonal eastward field (pre-reversal enhancement electric field, or PRE) caused by the interaction of neutral thermospheric wind with the longitudinal gradient in ionospheric conductivity that exists along the sunset terminator (e.g., Rishbeth, 1971; Heelis et al., 1974; Batista et al., 1986, Fejer et al., 1999; Abdu, 2001). It is now believed that ESF development depends on three main factors: (1) the linear growth rate for generalized RayleighTaylor instability process (Dungey, 1956), (2) the flux tube integrated Pedersen conductivity that controls the nonlinear development, and (3) density perturbations that are needed to act as a seed to trigger the instability growth. These density perturbations may be produced by different seeding sources: local variations in the vertical winds, electric fields, and gravity waves propagating upward from the troposphere (Singh et al., 1997; Abdu, 2001). More recently, Kudeki et al. (2007) have also suggested that the F-region zonal wind immediately after sunset plays a crucial role in controlling the structuring of bottomside F-region plasma and subsequent EPB development.

The seeding sources of ESF are the least understood aspect of this phenomena and observational evidence is currently limited. The main goal of the SpreadFEx campaign was to investigate the properties of gravity waves at ionospheric heights and their potential role in seeding Rayleigh-Taylor instabilities, strong equatorial spread-F and plasma bubble development. The campaign took place in Brazil during the equinox period (September-November 2005). Brazilian and US institutes utilized a broad range of instruments (all-sky imagers, digisondes, photometers, meteor/VHF radars, GPS receivers) to cover a large area of eastern Brazil where ESF is a common occurrence. A detailed overview of the campaign goals and measurements is given by Fritts et al. (2009). This paper focuses on characterizing the properties of the ionospheric equatorial plasma bubbles (EPBs) observed from two primary sites located $\sim 10^{\circ} \mathrm{S}$ from the magnetic equator.

\section{Observations and image analysis}

In order to obtain simultaneous optical measurements of the EPBs and of the gravity waves propagating through the upper atmosphere, observations were made using three all-sky CCD imagers: two from the Instituto Nacional de Pesquisas Espaciais (INPE) located at established sites at Cariri $\left(7.4^{\circ} \mathrm{S}\right.$, $\left.36.5^{\circ} \mathrm{W}\right)$, and Cachoeira Paulista $\left(22.7^{\circ} \mathrm{S}, 45.0^{\circ} \mathrm{W}\right)$, and one from Utah State University (USU) temporarily placed at São João d'Aliança, North of Brasilia $\left(14.8^{\circ} \mathrm{S}, 47.6^{\circ} \mathrm{W}\right)$.

Due to inclement weather at Cachoeira Paulista, this paper describes the results obtained by the two all-sky imagers located at Brasilia and Cariri. These two sites have approximately the same magnetic latitude $\left(9^{\circ} \mathrm{S}\right.$ for Cariri and $10^{\circ} \mathrm{S}$ for Brasilia) and are separated by $\sim 1500 \mathrm{~km}$, which allows overlapping fields of view for the depletion structures imaged in the thermospheric OI $(630.0 \mathrm{~nm})$ emission. This is illustrated in Fig. 1 which shows a map of Brazil with the location of these observation sites and the $1500 \times 1500 \mathrm{~km}$ areas covered by the OI $(630.0 \mathrm{~nm})$ data for the two imagers, using an expected emission altitude of $250 \mathrm{~km}$. The magnetic equator is also shown in the figure. The time differences between Universal Time (UT) and Local Solar Time (LST) are 3:10 h and 2:26 h for the Brasilia and Cariri sites, respectively, with Universal Time leading Local Solar Time.

Equatorial plasma irregularities have previously been studied extensively through optical observations of the F-region nightglow emissions on many occasions (e.g., Weber et al., 1978, Mendillo and Baumgardner, 1982; Rohrbaugh et al., 1989; Sahai et al., 1994; Taylor et al., 1997; Santana et al., 2001; Makela et al., 2001, 2004; Martinis et al., 2003; Kelley et al., 2002). Here we summarize the plasma depletion 
properties observed during the campaign using novel twostation measurements of the OI $630.0 \mathrm{~nm}$ emission which is produced at the bottomside of the ionospheric F-region, between 250 and $300 \mathrm{~km}$ of altitude. It is created by the following dissociative recombination process (Peterson and Van Zandt, 1969):

$\mathrm{O}_{2}+\mathrm{O}^{+} \rightarrow \mathrm{O}_{2}^{+}+\mathrm{O}$

$\mathrm{O}_{2}^{+}+e \rightarrow \mathrm{O}\left({ }^{1} \mathrm{D}\right)+\mathrm{O}\left({ }^{3} \mathrm{P}\right)$

$\mathrm{O}\left({ }^{1} \mathrm{D}\right) \rightarrow \mathrm{O}\left({ }^{3} \mathrm{P}\right)+h v(\lambda=630.0 \mathrm{~nm})$

The digital imaging systems at Brasilia and Cariri were both equipped with an all-sky telecentric lens and a computercontrolled filter wheel, providing the capability to sequentially observe gravity waves in the broadband mesospheric $\mathrm{OH}$ emission (mean altitude $\sim 87 \mathrm{~km}$ ), as well as the ionospheric OI $(630.0 \mathrm{~nm})$ emission $(\sim 250 \mathrm{~km})$ and the background sky continuum at $570 \mathrm{~nm}$. Other fainter mesospheric nightglow emission layers were also occasionally observed included the $\mathrm{O}_{2}(0,1)$ band and the OI $(557.7 \mathrm{~nm})$ emission line. Both imaging systems utilized similar $1024 \times 1024$ back thinned CCD array cameras. The data were $2 \times 2$ binned on chip, down to 512 by 512 pixels. Exposure times were $15 \mathrm{~s}$ for the $\mathrm{OH}$ data and $90-120 \mathrm{~s}$ for the OI $(630.0 \mathrm{~nm})$ data. These are well-proven field instruments and details of their specifications and operations can be found in Taylor et al. (1995), and Medeiros et al. (2001). Detailed studies of the short-period mesospheric gravity wave events observed during the campaign are given in accompanying papers Taylor et al. (2009), Vadas et al. (2009b).

For this campaign, the airglow observations were centered on two consecutive new moon periods; in September and October 2005. The first set of measurements started on 22 September and ended on 9 October (duration 17 nights), while the second set started on 22 October and ended on 9 November (duration 18 nights). Good quality extended dataset were obtained during 17 nights from Brasilia and 19 nights from Cariri. Due to the local weather conditions, only 8 of these nights are common to both sites: 24-25 September, 28-29 September, 29-30 September, 30 September-1 October, 1-2 October, 8-9 October for the first phase, and 26-27 October and 6-7 November for the second phase.

Before measuring the characteristics of the EPBs observed at both sites, it was necessary to preprocess the images. First, they were calibrated using the background starfield to determine the imager parameters (orientation and pixel scale size), then the stars were removed and the images "unwarped" to correct for the all-sky lens format. This is a well-developed procedure for airglow image analysis (e.g., Garcia et al., 1997; Pautet and Moreels, 2002). Figure 2 shows four examples of unwarped OI $(630.0 \mathrm{~nm})$ data comprising two simultaneous images, recorded on 1-2 October, during the first phase of the campaign (top row), and two images taken at the same time ( $\sim 2: 20$ UT) on two consecutive nights (25-26

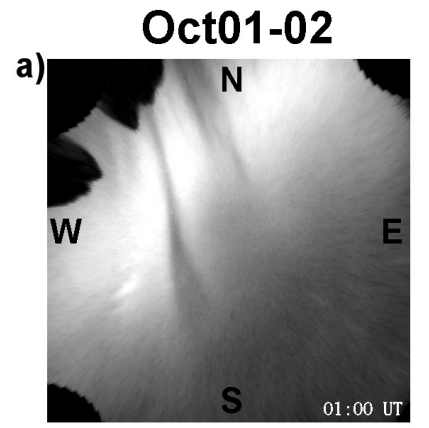

Brasilia

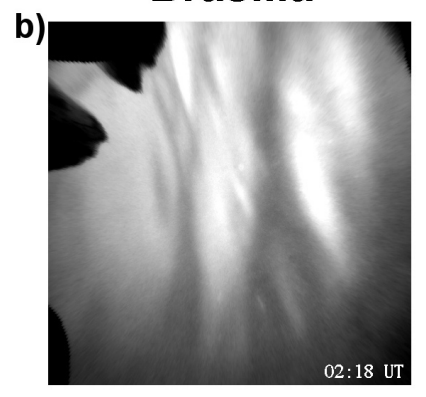

Oct25-26

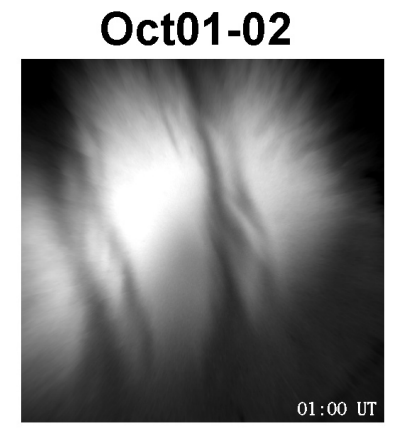

Cariri

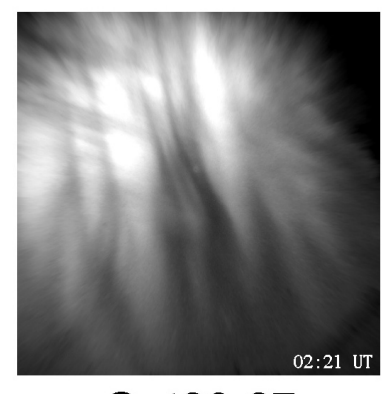

Oct26-27
Fig. 2. Examples of unwarped OI $(630 \mathrm{~nm})$ all-sky images $(1500 \times 1500 \mathrm{~km})$, showing ionospheric depletion structures, recorded from Brasilia (left) and Cariri (right) during the first phase (a) and second phase (b) of the campaign.

October and 26-27 October), during the second phase (bottom row), for Brasilia (left) and Cariri (right). The linear grid used for the image projection at $250 \mathrm{~km}$ was $1500 \times 1500 \mathrm{~km}$, resulting in a $\sim 3 \mathrm{~km} /$ pixel resolution, and each image is centered on the observation site.

For each night and site, the average drift velocity as a function of time was measured using the embedded depletion structures visible in the OI $(630.0 \mathrm{~nm})$ emission. Near the equator, this parameter has been showed to be approximately equal to the F-region neutral zonal winds velocity (Biondi et al., 1988; Basu et al., 1996). A method similar to the one developed by Pimenta et al. (2001) was applied to measure this parameter. The motion of the western wall of the depletions was determined, then the drift velocity was processed knowing the time between two images. In order to get a better precision, the displacement was measured between two odd (or even) pictures, giving a time separation of $\sim 300 \mathrm{~s}$ and an uncertainty of $\sim 10 \%$ in the speeds. Figure 3 plots the evolution of the drift velocity for several consecutive bubbles during the night of 1-2 October, above Brasilia. Bubbles \#4 to \#8 are shown in the all-sky image at 22:00 LST (top right). The individual bubble velocities overlap well and provide a good estimate of the average zonal velocity variation during the course of the night. Using this technique, the drift velocity was measured for the bubbles observed from Brasilia and Cariri during the campaign. 


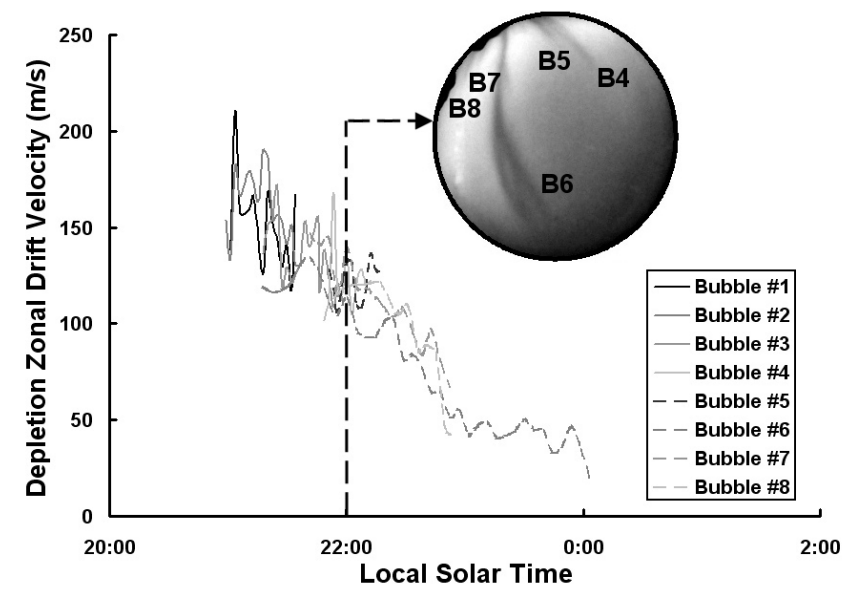

Fig. 3. Example of the drift velocity measurements for 8 bubbles observed during the night of 30 September-1 October from Brasilia.

\section{Results and discussion}

\subsection{EPB occurrence}

Ionospheric irregularities were detected every (cloudless) night from both sites but significant longitudinal variability in the depletion structures was evident (e.g., top row of Fig. 2). This result is discussed further later. It was also found that EPBs tended to exhibit more complex and extensive depletion patterns during the second observing period (as illustrated in the bottom pictures of Fig. 2). This results follows the expected seasonal variation in their occurrence frequency, with only a few depletions usually observed during the June to August period and a peak activity during the austral summer months, centered on the December solstice, when the solar flux is at its maximum (Sobral et al., 2002). This seasonal variation is also due to the longitude dependent magnetic declination (Abdu et al., 1981). To optimize these measurements, the SpreadFEx campaign was conducted during the equinoctial transition period which is also the time of the year when the solar terminator is aligned with the magnetic meridian; the magnetic eastward wind also tends to a maximum value as well as the longitudinal gradient in the integrated conductivity. The amplitude in the PRE in vertical drift and the irregularity occurrence can then reach a maximum during this part of the year (Abdu et al., 1981; Batista et al., 1986). The difference in the EPB development between the two phases of the campaign was consistent with the progress towards the December solstice.

\subsection{EPB drift velocities}

During both observing phases, the plasma bubbles exhibited a strong eastward motion. This zonal drift of the equatorial ionospheric F-region plasma was first described by Woodman (1972), using measurements from the Jicamarca inco-
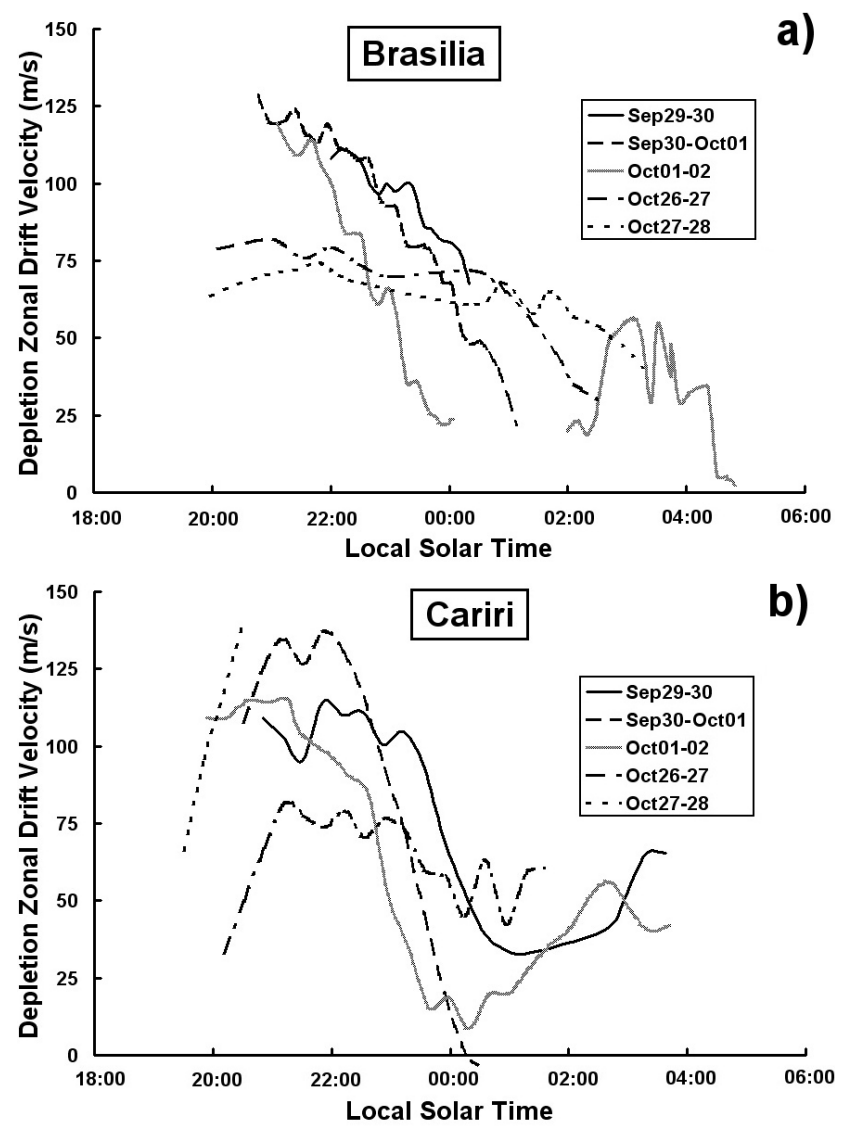

Fig. 4. Spread-F phase velocity as a function of Solar Local Time as observed from Brasilia (a) and Cariri (b), during 5 nights of extensive measurements.

herent scatter radar in Peru. However, it was previously predicted by Rishbeth (1971), as the zonal F-region wind dynamo driving the Pedersen currents and creating a vertical polarization electric field forces the plasma to drift at nearly the same velocity as the neutral wind.

In particular, measurements of the nighttime plasma drift velocity are important for studying thermosphere-ionosphere coupling. Figure 4 shows the average zonal drift velocities for Brasilia (a) and Cariri (b) for 5 nights with simultaneous depletion observations encompassing both phases of the campaign. During the first phase, the velocities at both sites were similar (e.g., 29-30 September, 30 September-1 October and 1-2 October), exhibiting a maximum of $\sim 120 \mathrm{~m} / \mathrm{s}$ around 21:30 LST, followed by a steady decrease over the next $2-3 \mathrm{~h}$ to $<30 \mathrm{~m} / \mathrm{s}$. In contrast, depletions observed during the second phase (25-26 October and 26-27 October) exhibited significantly lower drift velocities with a maximum of $\sim 75 \mathrm{~m} / \mathrm{s}$ around 22:00 LST and a slower reduction in velocity with time, and faded somewhat later in the night between 02:00 and 03:00 LST.

Post-midnight EPB enhancements were observed on several nights (e.g., 29-30 September from Cariri and 
1-2 October from both sites). These fainter bubbles also drifted eastward reaching a maximum velocity between 50 and $70 \mathrm{~m} / \mathrm{s}$ around 03:00 LST, before slowing down and fading just prior to sunrise. In most of the cases, the postmidnight EPBs were probably due to fossilized bubbles that exhibited no growth, moving through the fields of view (e.g., Basu et al., 1978). However on some nights, bubbles observed after midnight seemed to exhibit some growth (e.g., 23-24 October from Brasilia). These events are usually more frequent during solar minimum years, like 2005 (Fejer et al., 1999), but the lack of complementary data for the Brasilia site prevents any further investigation.

These results are summarized in Fig. 5 which combines phase 1 and 2 datasets to show the average velocity as a function of time for Brasilia and Cariri. These are compared with previous measurements made during the Guara campaign from Alcantara $\left(2.3^{\circ} \mathrm{S} ; 44.5^{\circ} \mathrm{W}\right)$, Brazil (Taylor et al., 1997), also during solar minimum conditions, and an empirical model using the Jicamarca $\left(12^{\circ} \mathrm{S}, 76.9^{\circ} \mathrm{W}\right)$ radar data obtained between 1968 and 1988 (Fejer et al., 1991). It is clear that during the first part of the night, the observations are in very good agreement with the expected Local Solar Time variability. However, after local midnight, the plasma drift velocity seems to be slightly higher $(\sim 10-20 \mathrm{~m} / \mathrm{s})$ compared to the Jicamarca model, as indicated by the frequent presence of fossilized EPBs observed during the SpreadFEx campaign.

Our results are therefore in good general agreement with previous observations made from the same longitudinal sector but there are some differences. For example, Mendillo and Baumgardner (1982) found maximum values around $200 \mathrm{~m} / \mathrm{s}$ from Ascension Island $\left(8.0^{\circ} \mathrm{S}, 14.4^{\circ} \mathrm{W}\right)$ while Pimenta et al. (2003), using data from Cariri $\left(7.4^{\circ} \mathrm{S}, 36.5^{\circ} \mathrm{W}\right)$ and Cachoeira Paulista $\left(22.7^{\circ} \mathrm{S}, 45.0^{\circ} \mathrm{W}\right)$, found two peaks in the ionospheric plasma zonal drift speed: one located near the magnetic equator $(\sim 160 \mathrm{~m} / \mathrm{s})$ and one around $19^{\circ} \mathrm{S}$ $(\sim 150 \mathrm{~m} / \mathrm{s})$. They attributed the minimum in velocity near $10^{\circ} \mathrm{S}(\sim 120 \mathrm{~m} / \mathrm{s})$, which corresponds to the magnetic latitude of the SpreadFEx sites, to a reduction in the zonal neutral wind. Another dataset obtained with the Cachoeira Paulista imager between 1998 and 2000 was analyzed by Arruda et al. (2006). For the equinoctial phase, corresponding to the SpreadFEx campaign period, they found a similar maximum drift velocity of $150 \mathrm{~m} / \mathrm{s}$. Finally, Martinis et al. (2003) have also made a latitudinal comparison using optical datasets acquired during the equinox period from two South American sites: Arequipa, Peru $\left(16.5^{\circ} \mathrm{S}, 71.5^{\circ} \mathrm{W}\right)$ and Tucuman, Argentina $\left(26.9^{\circ} \mathrm{S}, 65^{\circ} \mathrm{W}\right)$. They observed drift velocity peaks around 22:00 and 23:00 LST for Arequipa and Tucuman, respectively, with maximum values of $\sim 135$ and $\sim 115 \mathrm{~m} / \mathrm{s}$. These measurements were made from sites with magnetic latitudes that encompass our measurements from Brazil which are in closest agreement with the reported observations from Tucuman. As the reported results depend on the assumed altitude for the OI $(630.0 \mathrm{~nm})$ emissive layer

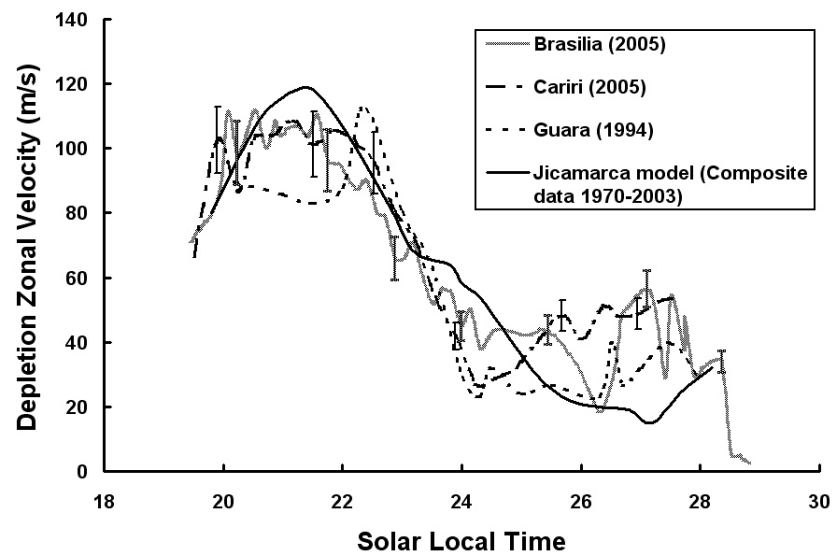

Fig. 5. Comparison of the average EPB phase velocities from Brasilia and Cariri, during the SpreadFEx campaign, using 17 and 19 nights, respectively, with an empirical model derived from the Jicamarca radar measurements by Fejer et al. (1991), and previous observations from Alcantara, Brazil, by Taylor et al. (1997).

which varies from 250 to $300 \mathrm{~km}$ (corresponding to a $20 \%$ increase in velocity), our SpreadFEx results are in good agreement with these prior studies. Moreover, our optical results have been shown to be consistent with coincident measurements made with a GPS IEC array operated from the Brasilia site during the campaign (J. S. Haase, personal communication, 2008).

It is also interesting to notice that the drift velocity from Cariri on September 30-1 October exhibited a brief westward motion before the bubble disappeared. A similar reversal has been reported by Taylor et al. (1997), using data from Alcantara, Brazil, who discussed its relation to a temporary reversal of the nocturnal F-layer dynamo electric field.

\subsection{EPB longitudinal comparison}

Longitudinal variability of the equatorial bubbles has been studied in the past using a variety of instrumentation: Maruyama amd Matuura (1984), used the topside soundings by the Ionospheric Sounding Satellite b (ISS-b) to determine a global distribution map of the ESF activity, while Tsunoda (1985) compared the seasonal scintillation activity using previously obtained datasets from several sites spread around the globe. More recently, Immel et al. (2004) utilized the FUV image data from the NASA IMAGE satellite to study the longitudinal variability of the zonal plasma drift speeds and their relation with the $D_{s t}$ index, during a limited 3 month-period (March to May 2002). Makela et al. (2004) compared their ionospheric airglow and GPS scintillation data acquired from Haleakala, Hawaii, with several previous studies, all from the Pacific sector. They also investigated the occurrence of the plasma bubbles and the possible location of their source region as a function of the time of the year. Most recently, Henderson et al. (2005) used the GUVI 


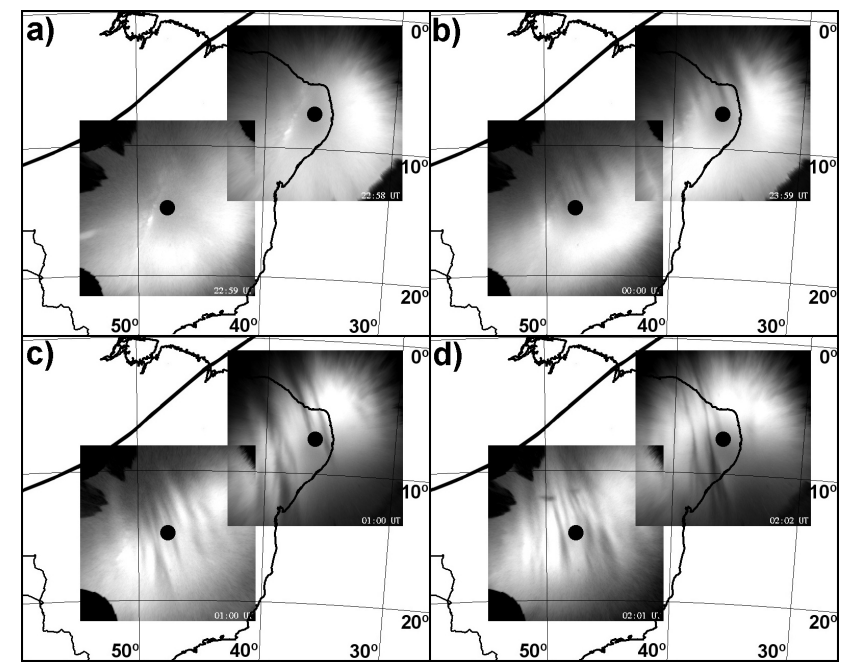

Fig. 6. Four plots showing the evolution of extensive plasma bubbles observed simultaneously from Brasilia and Cariri on 30 September-1 October. The data shown are hourly intervaled from 23:00 UT to 02:00 UT.

imager data on-board the NASA TIMED satellite to study the characteristics of the equatorial anomaly (EA) and the detection of the EPBs as a function of the longitudinal sector and season.

Moreover, several ionospheric airglow studies have been performed using two all-sky imagers (Otsuka et al., 2002; Martinis et al., 2003; Pimenta et al., 2003), mainly to investigate latitudinal variations in the EPB characteristics including their conjugate signatures. During the SpreadFEx campaign, the USU and INPE all-sky imagers were located at the same approximate magnetic latitude, separated by $\sim 1500 \mathrm{~km}$, to better sample the mesospheric gravity wave and ionospheric depletion structures over a large field of view. This configuration allowed the comparison of the longitudinal differences in the EPB generation, characteristics and evolution. Figure 6 is an example of the total field of view covered by the two imagers at Brasilia (left) and Cariri (right), for the night of 30 September-1 October. The image projections are in the same $1500 \times 1500 \mathrm{~km}$ format as Fig. 2, assuming an altitude of $250 \mathrm{~km}$ for the emissive layer, and centered on each site. The four maps correspond to the following times: 23:00 UT (a), 00:00 UT (b), 01:00 UT (c) and 02:00 UT (d). This night was typical of the several nights of coincident image measurements. Depletions were first detected around 23:00 UT, appearing near simultaneously in both camera fields of view (Fig. 6a). They were localized close to the magnetic equator and were very faint at this time. The bubbles grew in size and number over the next hour as shown in Fig. 6b, which displays a broad set of bubbles across both images. The bubbles were seen to move from the Brasilia field of view into the Cariri one in a coherent manner and they reached their maximum eastward zonal drift veloc-

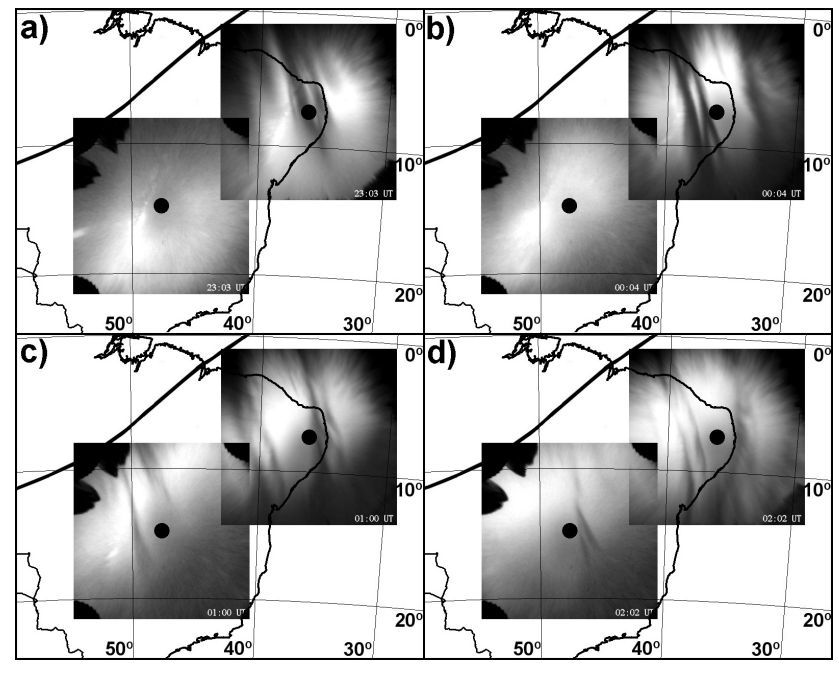

Fig. 7. Evolution of the bubbles structures observed simultaneously from Brasilia and Cariri during the following night (1-2 October) over the same time interval as Fig. 6. Note the lack of structure above Brasilia during the first two hours (panels $\mathbf{a}$ and $\mathbf{b}$ ).

ity (120-130 m/s) during this period. By 01:00 UT (Fig. 6c), the EPBs reached their maximum latitude/altitude extent and were starting to slow down. By 02:00 UT (Fig. 6d), the motion of the bubbles reduced to $0 \mathrm{~m} / \mathrm{s}$ and they subsequently faded over the next two hours. Observations from Brasilia were continued for 4 more hours until dawn and no further bubbles were detected.

Figure 7 shows the bubble display for the next night (1-2 October) plotted in a similar format. During this night, the EPB evolution was quite different from one site to the other: at 23:00 UT (Fig. 7a), the bubbles had already reached a mature phase above Cariri, but there was no evidence of depletions above Brasilia. By 00:00 UT (Fig. 7b), there were still no irregularities visible in the left projection but the ones in the right projection are fully developed with an estimated apex height above $750 \mathrm{~km}$. At 01:00 UT (Fig. 7c), EPBs, dominated by a single bubble, finally appeared above Brasilia. The main depletion grew significantly as it moved into the field of view from the West. At 02:00 UT (Fig. 7d), the depletions visible from both sites had started to slow down. Shortly thereafter, the strong depletion over Brasilia disappeared completely while the depletions to the East over Cariri remained evident until dawn. Later, a pair of fossilized bubbles entered the Brasilia field of view from the West.

To summarize the observations for these two consecutive nights West-East keograms are displayed on Fig. 8. The two top plots show the Brasilia data for 30 September-1 October (a) and 1-2 October (b), and the bottom plots the corresponding Cariri data ( $c$ and d). The difference between the EPBs observed on these two nights is clearly visible in the Brasilia keograms: several bubbles moved through the field of view during the first night, while just a single dominant 


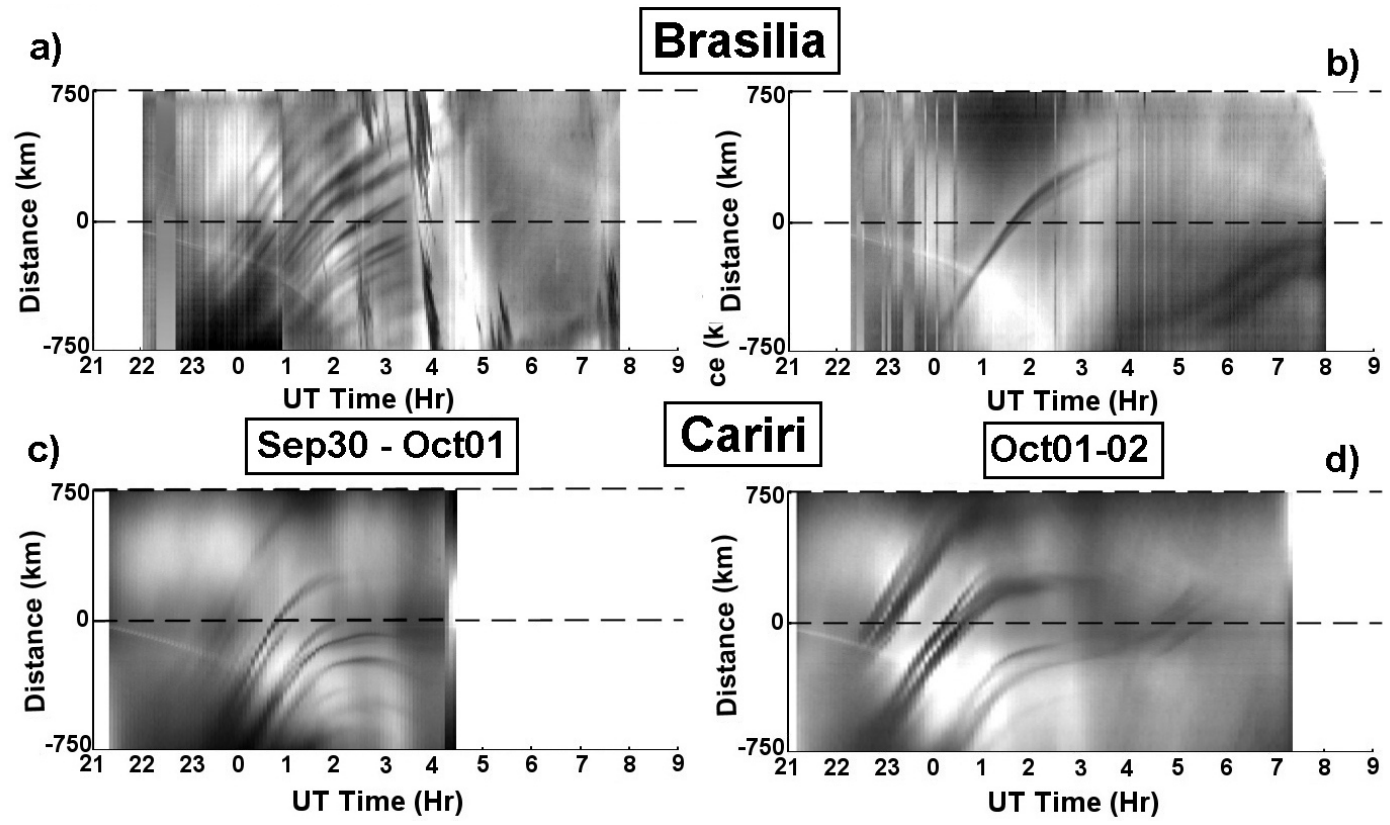

Fig. 8. West-East keograms showing the evolution of the plasma bubbles observed in the OI (630 nm) emission from Brasilia (top) and Cariri (bottom) during the nights of 30 September-1 October (left) and 1-2 October (right). The depletions appear as dark bands that are curved due to their change in velocity with time.

bubble occurred during the following night (note the pair of post-midnight fossilized EPBs evident in the bottom right of the keogram). In comparison, the keograms summarizing the Cariri data show similar patterns from one night to the next, with EPBs propagating between $\sim 22: 00$ and $\sim 02: 00$ UT. Comparison of the drift velocities also shows significant difference from these two sites. Figure 9 illustrates the correlation between the depletion zonal drift velocities at the same Local Solar Times above Brasilia and Cariri, for 30 September-1 October (a) and 1-2 October (b). Both plots show a high degree of correlation between the observed depletion velocities for each nights $(R=0.88$ and 0.90 , respectively). Comparison of the velocities on the first night (top plot) shows very similar behavior during the course of the night. However, on the second night, the velocities corresponding to the pre-midnight EPBs are substantially higher above Brasilia than above Cariri (typically $25 \mathrm{~m} / \mathrm{s}$ larger). In contrast, the fossilized post-midnight bubbles exhibited similar drift velocities $(\sim 50 \mathrm{~m} / \mathrm{s})$ at both sites.

These new measurements have revealed a surprising difference in both the morphology and the dynamics of the bubble structures imaged at the same time from two adjacent sites separated in longitude by only $1500 \mathrm{~km}$. The measurements were made during two consecutive nights, further illustrating the potential for differing bubble development on a night-to-night and regional basis. There are several factors that may explain such differences:

- The influence of a different magnetic declination angle on the PRE arising can modify the seasonal pattern of bubble occurrence such as between the Peruvian and Brazilian sectors (Abdu et al., 1981). However, this angle is almost identical for Brasilia and Cariri and the data were all obtained around the equinox.

- The vertical drift and height of the F-layer which control the instability growth rate. Due to the close proximity of the observation sites, it is unlikely that these parameters would have been significantly different. However, no ionosonde or radar data were available for the Brasilia site, and it was not possible to compare with the ionosonde and radar measurements made around Cariri.

- The density gradient and the thermospheric zonal wind which control the intensity of the PRE through the E$F$ regions electrodynamical coupling process. In the case of the comparison between 30 September-1 October and 1-2 October, the zonal plasma drift velocity was different at the two sites, at least during the first part of the night. Subsequently, the intensity of the PRE may have been different from one longitude to the other, inducing a modification in the EPB generation.

- The regional variation in the local density perturbation acting as a seeding source. In particular, the differences in the gravity waves propagating upward from the troposphere which act as perturbation sources triggering the Rayleigh-Taylor instability process (Vadas et al., 2009b). 

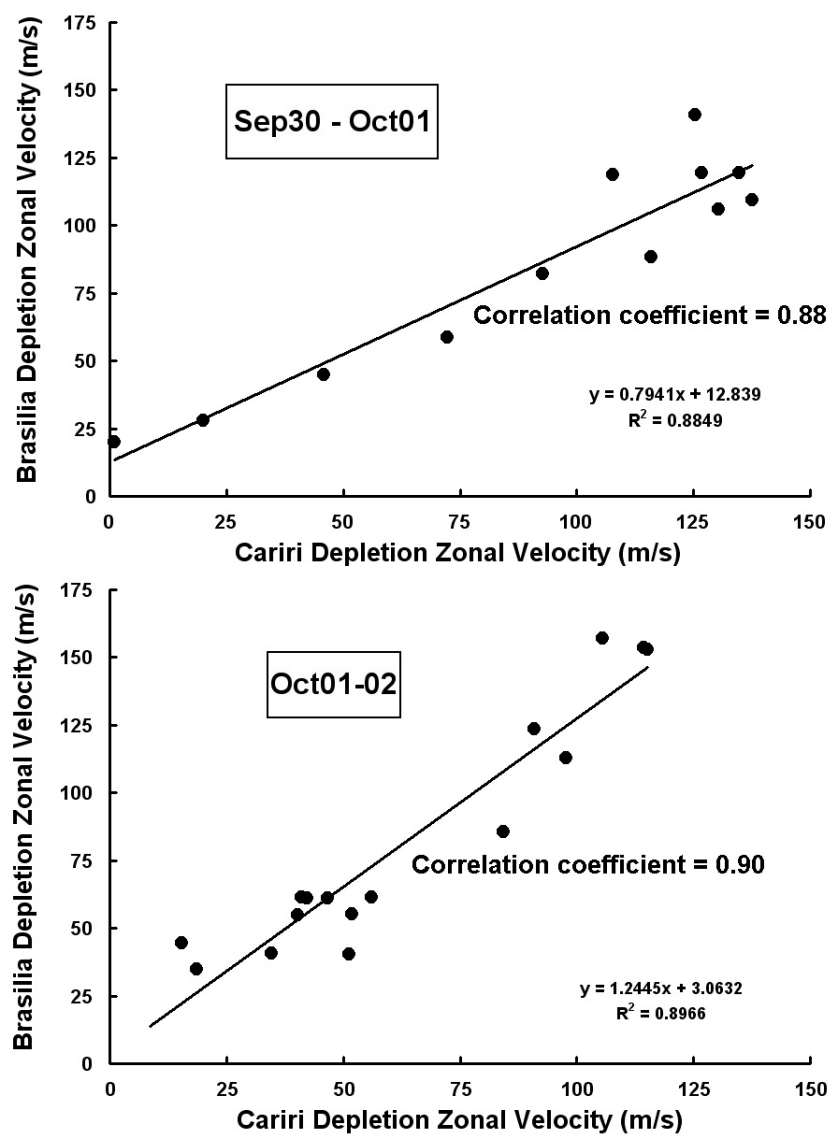

Fig. 9. Plots showing the correlation between the zonal drift velocities of the depletions observed from Brasilia and Cariri during the nights of 30 September-1 October (a) and 1-2 October (b). Note the different gradients.

Several previous studies have suggested the possible role of the gravity waves on the generation and/or development of the ESF events. The possibility of a remote source such as tropospheric convection activity producing upward propagating gravity waves was first proposed by Rottger (1981). Tsunoda and White (1981) observed the bottomside altitude modulation of the F-layer preceding the ESF bubbles, using ALTAIR radar data, while Kelley et al. (1981) noted the role of gravity waves on the modulation of large-scale plumes. The need of a seed perturbation created by gravity waves was suggested again by Hanson et al. (1986), based on modeled growth time for Rayleigh-Taylor mechanism working on a layer bottomside initially lifted up by an eastward electric field. In 1998, Kil and Heelis reported that longitudinal features in the irregularity occurrence global pattern could be explained by a seed source, possibly associated with the local tropospheric convection activity. McClure et al. (1998) have also associated certain features in the EPB distribution with seasonal migration of the ITCZ (inter-tropical convergence zone), which defines the geographical zones of tropospheric convection.

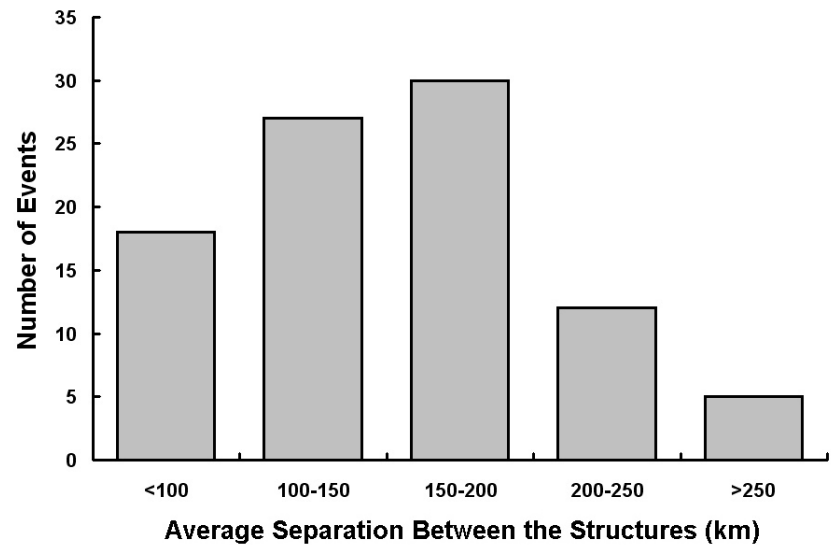

Fig. 10. Histogram plot showing the distribution of the average separations between two consecutive bubble structures observed from Brasilia and Cariri.

Therefore, it is quiet possible that the local gravity wave activity may be an explanation for the day-to-day and longitudinal differences observed in the EPB generation and propagation during the SpreadFEx campaign. A primary goal of this campaign was to investigate the properties of gravity waves at ionospheric heights and their potential role in seeding Rayleigh-Taylor instabilities, strong equatorial spread-F and plasma bubble development. Detailed studies of the convective sources that may have generated gravity waves able to propagate up to the ionosphere to seed plasma irregularities are given by Taylor et al. (2009); Vadas and Fritts (2009); and Vadas et al. (2009a, b). The impact of such gravity waves on the spread-F generation and evolution has also been investigated by Fritts et al. (2008) and Fritts and Vadas (2008). In particular, these studies conclude that several of the gravity wave events observed over Brasilia may have penetrated to high enough altitudes to potentially seed ESF.

To further help investigate the influence of gravity waves on the EPB generation we have also determined the horizontal scale sizes of the structures observed in the ionospheric irregularities during this campaign. These bubble irregularities growing under Rayleigh-Taylor instability mechanism spread into a wide spectrum of scale sizes (Haerendel, 1973), from a few tens of meters to hundreds of kilometers. Figure 10 is a histogram plot showing the distribution of the separations between adjacent depletion structures observed from Brasilia and Cariri. Although significant fine scale structures are evident in the image data (e.g., Fig. 2), due to the often rapid evolution of the smaller features, they were not always easy to track, and we have limited the horizontal scale sizes in the histogram plot to $>50 \mathrm{~km}$. The majority of the bubbles exhibited separation of 100 to $200 \mathrm{~km}$. In their paper, Takahashi et al. (2009) studied the possible correlation between the horizontal wavelengths of the gravity waves observed while they were propagating through the MLT layer and the size of the structures of the plasma irregularities. 
Their results suggest a significant correlation between the observed ionospheric bubbles scales and the mesospheric gravity wave horizontal wavelengths.

\subsection{Influence of the geomagnetic activity}

The magnetic activity induced by the solar wind may modify the development of the ionospheric bubbles in different ways (Kelley et al., 2000; Sobral et al., 2002): a post-sunset penetration electric field occurring over equatorial latitudes, associated with magnetospheric disturbances, especially auroral substorms, up to $K_{p}=5$ and preceding the ESF onset by at least $4 \mathrm{~h}$ may inhibit its development, while a $K_{p}>5$ during the same period, or an increase in $K_{p}$ occurring around sunset, may increase the bubble occurrence (Sobral et al., 2002).

However, no significant geomagnetic perturbation occurred during the whole campaign. Only four 3-hr intervals reached the G1 geomagnetic storm level $\left(K_{p}=5\right)$ : 5 October, 7 October, 30 October and 2 November, and the data available on these nights suggest no significant increase in bubble activity. The other days were magnetically quiet; consequently, we can consider that there was no significant influence of the geomagnetic activity on the ESF development during the campaign.

\section{Summary}

As part of the SpreadFEx campaign, optical observations of the ionospheric OI $(630 \mathrm{~nm})$ emission layer were conducted from two sites (Brasilia and Cariri) with similar magnetic latitudes and overlapping fields of view, in order to simultaneously study the generation, structure and evolution of the plasma depletions in close proximity of the magnetic equator. Extensive data were obtained on 17 nights from Brasilia and 19 nights from Cariri during two observation phases centered on the September and October 2005 new moon periods. Common measurements were limited to 8 nights but they have provided an important dataset for characterizing the depletions and to perform a novel longitudinal investigation of localized variability (bubble structure and occurrence).

EPBs were observed on every clear night during the campaign, exhibiting the same general evolution as previously reported (generation after sunset followed by poleward expansion, corresponding to the upward instability growth over the equator). The observed eastward drift maximized at $\sim 120 \mathrm{~m} / \mathrm{s}$ just before 22:00 LST, then decreased systematically until local solar midnight, thereafter the depletions faded with time. These results are in good quantitative agreement with previous measurements from the same longitudinal sector, under similar geomagnetic and solar conditions (e.g., Taylor et al., 1997; Sobral et al., 2002; Martinis et al., 2003). On several nights, fossilized post-midnight EPBs were observed, often until dawn, with lower eastward drift velocities (maximum $\sim 50 \mathrm{~m} / \mathrm{s}$ ). Occasionally, the drift ve- locity also showed a short-lived westward motion possibly due to a temporary reversal in the normal F-layer dynamo electric field.

The overlapping fields of view of the two station measurements have revealed surprising day-to-day variations in the time generation and characteristics of the bubbles, both sites being at approximately the same magnetic latitude (9$10^{\circ} \mathrm{S}$ ) and separated by only $\sim 1500 \mathrm{~km}$. Differences in the height of the F-layer, in the zonal thermospheric wind, in the longitudinal gradient in the flux tube integrated conductivity, or in the seeding sources may account for the different evolution in the observed EPBs. During 7 of the 8 nights of common data, the growth of the EPBs occurred near simultaneously throughout the joint observation region. However, on the night of 1-2 October, depletions were restricted in their occurrence to the Cariri region with no development over Brasilia for at least two hours. Subsequent bubble structure at Brasilia was limited and faded rapidly while the Cariri depletions were observed continuously until dawn. As it is difficult to determine the exact cause of this longitudinal difference, the data are consistent with a more localized origin for the seeding/growth of the plasma bubbles observed on this night, possibly associated with tropospheric convection (McClure et al., 1998; Vadas et al., 2009b). Associated studies presenting analyses of the data gathered during the SpreadFEx campaign suggest a correlation between tropospheric convective activity, gravity wave propagation into the lower ionosphere, and the generation of the plasma bubbles (Fritts et al., 2008; Fritts and Vadas, 2008; Takahashi et al., 2009; Vadas and Fritts, 2009; Vadas et al., 2009a, b).

As suggested by Makela et al. (2004), further studies are needed using data from multiple locations closely spaced in longitude to investigate differences in longitudinal occurrence and structures of equatorial plasma bubbles not accounted for in current theories (e.g., Tsunoda, 1985; Maruyama and Matuura, 1984).

Acknowledgements. The SpreadFEx field program and data analysis were supported by NASA under contracts NNH04CC67C and NAS5-02036. We would like to acknowledge Edivan Bataglin, for allowing us to set up the USU camera at Fazenda Isabel, near Brasilia, and for providing infrastructure support. We also would like to thank the Mayor House and House of Representatives of São João d'Aliança, especially Julio Sempere and Nilson Deodoro Cândido for all the logistical support during the campaign.

Topical Editor U.-P. Hoppe thanks two anonymous referees for their help in evaluating this paper.

\section{References}

Abdu, M. A., Bittencourt, J. A., and Batista, I. S.: Magnetic declination control of the equatorial $F$ region dynamo field development and spread-F, J. Geophys. Res., 86, 11443-11446, 1981.

Abdu, M. A.: Outstanding problems in the equatorial ionospherethermosphere electrodynamics relevant to spread F, J. Atmos. Terr. Phys., 63, 869-884, 2001. 
Abdu, M. A., de Souza, J. R., Batista, I. S., and Sobral, J. H. A.: Equatorial spread-F statistics and empirical representation for IRI: a regional model for the Brazilian longitude sector, Adv. Space Res., 31, 703-716, 2003.

Arruda, D. C. S., Sobral, J. H. A., Abdu, M. A., Castilho, V. M., Takahashi, H., Medeiros, A. F., and Buriti, R. A.: Theoritical and experimental zonal drift velocities of the ionospheric plasma bubbles over the Brazilian region, Adv. Space Res., 38, 26102614, 2006.

Batista, I. S., Abdu, M. A., and Bittencourt, J. A.: Equatorial Fregion vertical plasma drifts: seasonal and longitudinal asymmetries in the American sector, J. Geophys. Res., 91, 12055-12064, 1986.

Basu, S., Basu, Su., Aarons, J., McClure, J. P., and Cousins, M. D.: On the coexistence of kilometer- and meter-scale irregularities in the nighttime equatorial F region, J. Geophys. Res., 83, 42194226, 1978.

Basu, S., Kudeki, E., Basu, Su., Valladares, C. E., Weber, E .J., Zengingonul, H. P., Batthacharyya, S., Sheehan, R., Meriwether, J. W., Biondi, M. A., Kuenzler, H., and Espinoza, J.: Scintillations, plasma drifts, and neutral winds in the equatorial ionosphere after sunset, J. Geophys. Res., 101(A12), 26795-26809, 1996.

Basu, S., Groves, K. M., Quinn, J. M., and Doherty, P.: A comparison of TEC fluctuation and scintillations at Ascension Island, J. Atmos. Sol. Terr. Phys., 61, 1219-1226, 1999.

Biondi, M. A., Meriwether Jr., J. W., Fejer, B. G., and Woodman, R.: Measurements of the dynamics and coupling of the equatorial thermosphere and the F-region ionosphere over Peru, J. Atmos. Terr. Phys., 50, 937-942, 1988.

Booker, H. G. and Wells, H. W.: Scattering of radio waves by the F-region of the ionosphere, J. Geophys. Res., 43, 249-256, 1938.

Dungey, J. W.: Convective diffusion in the equatorial F region, J. Atmos. Solar-Terr. Phys., 9, 304-310, 1956.

Fejer, B. G., Kudeki, E., and Farley, D. T.: Equatorial F-region plasma drifts, J. Geophys. Res., 90, 12249-12255, 1985.

Fejer, B. G., de Paula, E. R., Gonzalez, S. A., and Woodman, R. F.: Average vertical and zonal F-region plasma drifts over Jicamarca, J. Geophys. Res., 96, 13901-13906, 1991.

Fejer, B. G., Scherliess, L., and de Paula, E. R.: Effects of the vertical plasma drift velocity on the generation and evolution of equatorial spread F, J. Geophys. Res., 104, 19859-19870, 1999.

Fritts, D. C., Vadas, S. L., Riggin, D. M., Abdu, M. A., Batista, I. S., Takahashi, H., Medeiros, A., Kamalabadi, F., Liu, H.-L., Fejer, B. G., and Taylor, M. J.: Gravity wave and tidal influences on equatorial spread $\mathrm{F}$ based on observations during the Spread F Experiment (SpreadFEx), Ann. Geophys., 26, 3235-3252, 2008, http://www.ann-geophys.net/26/3235/2008/.

Fritts, D. C., Abdu, M. A., Batista, B. R., Batista, I. S., Batista, P. P., Buriti, R., Clemesha, B. R., Dautermann, T., de Paula, E. R., Fechine, B. J., Fejer, B. G., Gobbi, D., Haase, J., Kamalabadi, F., Kherani, E. A., Laughman, B., Lima, P. P., Liu, H.-L., Medeiros, A., Pautet, P.-D., Riggin, D. M., Rodrigues, F. S., São Sabbas, F., Sobral, J. H. A., Stamus, P., Takahashi, H., Taylor, M. J., Vadas, S. L., Vargas, F., and Wrasse, C. M.: Overview and summary of the Spread F Experiment (SpreadFEx), Ann. Geophys., 27, 2141-2155, 2009, http://www.ann-geophys.net/27/2141/2009/.

Fritts, D. C. and Vadas, S. L.: Gravity wave penetration into the thermosphere: sensitivity to solar cycle variations and mean winds, Ann. Geophys., 26, 3841-3861, 2008, http://www.ann-geophys.net/26/3841/2008/.

Garcia, F. J., Taylor, M. J., and Kelley, M. C.: Two-dimensional spectral analysis of mesospheric airglow image data, Appl. Optics, 36(29), 7374-7385, 1997.

Haerendel, G. E.: Theory of equatorial spread-F, Report, Maxplanck-Institut fur Extraterre. Phys., Garching, Germany, 1973.

Haerendel, G. E., Eccles, J. V., and Çakir, S.: Theory of modeling the equatorial evening ionosphere and the origin of the shear in the horizontal plasma flow, J. Geophys. Res., 97(A2), 12091223, 1992.

Hanson, W. B., Cragin, B. L., and Dennis, A.: The effect of vertical drift on the equatorial F-region stability, J. Atmos. Terr. Phys., 48, 205-212, 1986.

Heelis, R. A., Kendall, P. C., Moffet, R. J., Windle, D. W., and Rishbeth, H.: Electrical coupling of the $\mathrm{E}$ and $\mathrm{F}$ regions and its effect on the F region drifts and winds, Planet. Space Sci., 22, 743-756, 1974.

Henderson, S. B., Swenson, C. M., Christensen, A. B., and Paxton, L. J.: Morphology of the equatorial anomaly and equatorial plasma bubbles using image subspace analysis of Global Ultraviolet Imager data, J. Geophys. Res., 110, A11306, doi:10.1029/2005JA011080, 2005.

Immel, T. J., Frey, H. U., Mende, S. B., and Sagawa, E.: Global observations of the zonal drift speed of equatorial ionospheric plasma bubbles, Ann. Geophys., 22, 3099-3107, 2004, http://www.ann-geophys.net/22/3099/2004/.

Jahn, J.-M., LaBelle, J., and Pfaff, R. G.: DC electric field measurements with the Guara spread-F rocket, Geophys. Res. Lett., 27(13), 1695-1698, 1997.

Kelley, M. C., Larsen, M. F., and LaHoz, C.: Gravity wave initiation of equatorial spread F: a case study, J. Geophys. Res., 86, 90879100, 1981.

Kelley, M. C., Garcia, F., Makela, J. J., Fan, T., Mak, E., Sia, C., and Alcocer, D.: Highly structured tropical airglow and TEC signatures during strong geomagnetic activity, Geophys. Res. Lett., 27(4), 465-468, 2000.

Kelley, M. C., Makela, J. J., Ledvina, B. M., and Kintner, P. M.: Observations of equatorial spread-F from Haleakala, Hawaii, Geophys. Res. Lett., 29, 20, doi:10.1029/2002GL015509, 2002.

Kil, H. and Heelis, R. A.: Global distribution of density irregularities in the equatorial ionosphere, J. Geophys. Res., 103, 407-417, 1998.

Makela, J. J., Kelley, M. C., Gonzalez, S. A., Aponte, N., and McCoy, R. P.: Ionospheric topography maps using multiple wavelength all-sky images, J. Geophys. Res., 106(A12), 2916129174, 2001.

Makela, J. J., Ledvina, B. M., Kelley, M. C., and Kintner, P. M.: Analysis of the seasonal variations of equatorial plasma bubble occurrence observed from Haleakala, Hawaii, Ann. Geophys., 22, 3109-3121, 2004, http://www.ann-geophys.net/22/3109/2004/.

Martinis, C., Eccles, J. V., Baumgardner, J., Manzano, J., and Mendillo, M.: Latitude dependence of zonal plasma drifts obtained from dual-site airglow observations, J. Geophys. Res., 108(A3), 1129, doi:10.1029/2002JA009462, 2003.

Maruyama, T. and Matuura, N.: Longitudinal variability of annual changes in activity of equatorial spread $F$ and 
plasma bubbles, J. Geophys. Res., 89(A12), 10903-10912, doi:10.1029/JA089iA12p10903, 1984.

McClure, J. P., Singh, S., Bamgboye, D.K., Johnson, F. S., and Kil, $\mathrm{H}$.: Occurrence of equatorial $\mathrm{F}$ region irregularities: Evidence for tropospheric seeding, J. Geophys. Res., 103(A12), 2911929135, 1998.

Medeiros, A. F., Taylor, M. J., Takahashi, H., Batista, P. P., and Gobbi, D.: An unusual airglow wave event observed at Cachoeira Paulista $23^{\circ}$ S, Adv. Space Res., 27, 1749-1754, 2001.

Mendillo, M. and Baumgardner, J.: Airglow characteristics of equatorial plasma depletions, J. Geophys. Res., 87(A9), 7641-7652, doi:10.1029/JA087iA09p07641, 1982.

Mendillo, M. and Tyler, A.: Geometry of depleted plasma regions in the equatorial ionosphere, J. Geophys. Res., 88(A7), 5778-5782, doi:10.1029/JA088iA07p05778, 1983.

Moore, J. G. and Weber, E. J.: OI 6300 and 7774 airglow measurements of equatorial plasma depletions, J. Atmos. Terr. Phys., 43, 851-858, 1981

Ossakow, S. L.: Spread-F theories - A review, J. Atmos. Terres. Phys., 43, 437-452, 1981.

Otsuka, Y., Shiokawa, K., Ogawa, T., and Wilkinson, P.: Geomagnetic conjugate of equatorial airglow depletions, Geophys. Res. Lett., 29(15), 1753, doi:10.1029/2002GL015347, 2002.

Pautet, P.-D. and Moreels, G.: Ground-based satellite-type images of the upper-atmosphere emissive layer, Appl. Optics, 41(5), 823-831, 2002.

Peterson, V. L. and Van Zandt, T. E.: O $\left({ }^{1} \mathrm{D}\right)$ quenching in the ionospheric F-region, Planet. Space Sci., 17, 1725-1736, 1969.

Pimenta, A. A., Fagundes, P. R., Bittencourt, J. A., Sahai, Y., Gobbi, D., Taylor, M. J., and Takahashi, H.: Ionospheric plasma bubble zonal drift: A methodology using OI $630 \mathrm{~nm}$ all-sky imaging systems, Adv. Space Res., 27, 1219-1224, 2001.

Pimenta, A. A., Bittencourt, J. A., Fagundès, P. R., Sahai, Y., Buriti, R. A., Takahashi, H., and Taylor, M. J.: Ionospheric plasma bubble zonal drifts over the tropical region: a study using OI $630 \mathrm{~nm}$ emission all-sky images, J. Atmos. Terr. Phys., 65, 1117-1126, 2003

Rishbeth, H.: Polarization fields produced by winds in the equatorial F region, Planet. Space Sci., 19, 357-369, 1971.

Rohrbaugh, R. P., Hanson, W. B., Tinsley, B. A., Cragin, B. L., and McClure, J. P.: Images of transequatorial bubbles based on field-aligned airglow observations from Haleakala in 1984-1986, J. Geophys. Res., 94(A6), 6763-6770, doi:10.1029/JA094iA06p06763, 1989.

Rottger, J.: Equatorial spread-F by electric fields and atmospheric gravity waves generated by thunderstorms, J. Atmos. Terr. Phys., 43, 453-462, 1981

Sahai, Y., Aarons, J., Mendillo, M., Baumgardner, J., Bittencourt, J. A., and Takahashi, H.: OI $630 \mathrm{~nm}$ imaging observations of equatorial plasma depletions at $16^{\circ} \mathrm{S}$ dip latitude, J. Atmos. Terr. Phys., 56, 1461-1475, 1994.

Sales, G. S., Reinisch, B. W., Scali, J. L., Dozois, C., Bullet, T. W., Weber, E. J., and Ning, P.: Spread-F and the structure of equatorial ionization depletions in the southern anomaly region, J. Geophys. Res., 101(A12), 26819-26827, doi:10.1029/96JA01946, 1996.

Santana, D. C., Sobral, J. H. A., Takahashi, H., and Taylor, M. J.: Optical studies of the ionospheric irregularities over the Brazilian region by nocturnal images of the OI $630 \mathrm{~nm}$ emission, Adv.
Space Res., 27(6), 1207-1212, 2001.

Singh, S., Johnson, F. S., and Power, R. A.: Gravity wave seeding of equatorial plasma bubbles, J. Geophys. Res., 102(A4), 73997410, doi:10.1029/96JA03998, 1997.

Sobral, J. H. A., Abdu, M. A., Takahashi, H., Taylor, M. J., de Paula, E. R., Zamlutti, C. J., de Aquino, M. G., and Borba, G. L.: Ionospheric plasma bubble climatology over Brazil based on 22 years (1977-1998) of $630 \mathrm{~nm}$ airglow observations, J. Atmos. Terr. Phys., 64, 1517-1524, 2002.

Takahashi, H., Taylor, M. J., Pautet, P.-D., Medeiros, A. F., Gobbi, D., Wrasse, C. M., Fechine, J., Abdu, M. A., Batista, I. S., Paula, E., Sobral, J. H. A., Arruda, D., Vadas, S. L., Sabbas, F. S., and Fritts, D. C.: Simultaneous observation of ionospheric plasma bubbles and mesospheric gravity waves during the SpreadFEx Campaign, Ann. Geophys., 27, 1477-1487, 2009, http://www.ann-geophys.net/27/1477/2009/.

Taylor, M. J., Bishop, M. B., and Taylor, V.: All-sky measurements of short period waves imaged in the OI $(557.7 \mathrm{~nm}), \mathrm{Na}$ $(589.2 \mathrm{~nm})$ and near infrared $\mathrm{OH}$ and $\mathrm{O} 2(0,1)$ nightglow emissions during the ALOHA-93 campaign, Geophys. Res. Lett., 22(20), 2833-2836, doi:10.1016/S0273-1177(97)00161-0, 1995.

Taylor, M. J., Eccles, J. V., LaBelle, J., and Sobral, J. H. A.: High resolution OI $(630 \mathrm{~nm})$ image measurements of F-region depletion drifts during the Guára campaign, Geophys. Res. Lett., 24, 1699-1702, 1997.

Taylor, M. J., Pautet, P.-D., Medeiros, A. F., Buriti, R., Fechine, J., Fritts, D. C., Vadas, S. L., Takahashi, H., and So Sabbas, F. T.: Characteristics of mesospheric gravity waves near the magnetic equator, Brazil, during the SpreadFEx campaign, Ann. Geophys., 27, 461-472, 2009, http://www.ann-geophys.net/27/461/2009/.

Tsunoda, R. T. and White, B. R.: On the generation and growth of equatorial backscatter plumes, 1 - Wave structure in the bottomside F layer, J. Geophys. Res., 86(A5), 3610-3616, doi:10.1029/JA086iA05p03610, 1981.

Tsunoda, R. T.: Control of the seasonal and longitudinal occurrence of equatorial scintillations by the longitudinal gradient in integrated E region Pedersen conductivity, J. Geophys. Res., 90(A1), 447-456, doi:10.1029/JA090iA01p00447, 1985.

Vadas, S. L. and Fritts, D. C.: Reconstruction of the gravity wave field from convective plumes via ray tracing, Ann. Geophys., 27, 147-177, 2009, http://www.ann-geophys.net/27/147/2009/.

Vadas, S. L., Taylor, M. J., Pautet, P.-D., Stamus, P. A., Fritts, D. C., Liu, H.-L., So Sabbas, F. T., Rampinelli, V. T., Batista, P., and Takahashi, H.: Convection: the likely source of the medium-scale gravity waves observed in the $\mathrm{OH}$ airglow layer near Brasilia, Brazil, during the SpreadFEx campaign, Ann. Geophys., 27, 231-259, 2009a, http://www.ann-geophys.net/27/231/2009/.

Vadas, S. L., Fritts, D. C., Pautet, P.-D., Taylor, M. J., Liu, H.L., Batista, P., Takahashi, H., São Sabbas, F. T., Stamus, P., Medeiros, A. F., Buriti, R. A., and Fechine, J.: Amplitudes, scales, and variability of gravity waves in the thermosphere from convective plumes over Brazil, Ann. Geophys., to be submitted, $2009 \mathrm{~b}$.

Weber, E. J., Buchau, J., Eatther, R. H., and Mende, S. B.: NorthSouth aligned equatorial airglow depletions, J. Geophys. Res., 83, 712-716, 1978

Woodman, R. F.: East-west ionospheric drifts at the magnetic equator, Space Res., 81, 5447-5466, 1972. 